\title{
EXPREIMENTAL STUDY ON MECHANICAL AND TRIBOLOGICAL PROPERTIES OF BIODEGRADABLE NATURAL FIBER COMPOSITES
}

\section{NAGA LAKSHMI PAVANI PUVVADA \& POLARAO RONANKI}

Department of Mechanical Engineering, GMR Institute of Technology, Rajam, Andhra Pradesh, India

\begin{abstract}
Natural fibers are the low cost and environment friendly materials with improved mechanical properties which can be enhanced by combining natural fibers in different compositions. Over the last century, polymers have emerged as one of the most indispensable components used in everyday life, epoxy or poly-epoxide being one such example. Until recently, synthetic filler materials have been the preferred choice for reinforcement of epoxy to improve its toughness. However, natural filler and fibrous materials are emerging as suitable alternatives to synthetic materials for reinforcing polymers such as epoxy due to their environment friendliness, high abundance, renewability, and cost effectiveness. Several research efforts have been put to study the effectiveness of natural fiber-based materials on the mechanical behavior of epoxy composites, focusing mainly on fibers and their weight percentage within the composites. Snail shells and goat horns are rich in calcium and protein so that high strength is attained in composites. In this work, it is planned to fabricate composites with two natural fillers (snail shell powder and goat horn powder) and goat hair as fiber. The Composite specimens prepared are used to study the Mechanical and Tribological properties and compared with the other natural fiber-based composites. In this work, natural fiber composites are prepared with various combinations of fillers and fibers which are composed of Horn powder, Snail Shell powder as fillers. Composites are prepared using molds and are cut to ASTM standards and testing of mechanical properties and Tribological tests are also carried out on the composite specimens.
\end{abstract}

KEYWORDS: Natural composites; Goat horns; Goat hair; Snail shells, Tribological properties \& Bio waste

Received: Jun 09, 2020; Accepted: Jun 29, 2020; Published: Jul 16, 2020; Paper Id.: IJMPERDJUN2020341

\section{INTRODUCTION}

The increasing attention towards utilization of natural fibers makes searching for alternatives to synthetic fibers. The composites made of animal and plant based can be used for such cases. The animal based composites consisting of horns which consist of high amount of protein have been used for testing of Tribological properties. The composites are fabricated using bio-waste horn, fiber (HF) and phenol formaldehyde (PF) resin to replace asbestos in brake pads. The optimized results have shown that the specimen has less water absorption and surface roughness, high hardness, compression strength and COF, can be a replacement of the asbestos specimen in the preparation of brake pads [1]. The eco-friendly hair fiber reinforced polymeric composites possess satisfactory mechanical properties and are renewable, cheap, biodegradable and recyclable. These composite exhibits higher flexural strength and flexural modulus [2]. Addition of fillers in the preparation of composites along with matrix can improve the mechanical properties. The reason for this could be elimination of matrix porosity with uniform distribution of fillers along the composite structure [3]. The mechanical behavior and wear resistance of the epoxy polymer matrix filled with snail shell particles have shown significant enhancement when the matrix is filled with highest amount of snail shell particles of smaller size [4]. The mollusk shells are known for rich in calcium 
carbonates and macromolecules like proteins and polysaccharides. The composites made of this can be used as filler materials in concretes in construction of civil structures and artistic composites as they exhibit excellent mechanical properties [5]. The polymer Methyl methacrylate reinforced with snail shell powder can be used for dental application as they show good mechanical and Tribological properties. The wear resistance of these composites is increased with the addition of snail shell powder as additives in different percentages, sample made of $12 \%$ wt snail shell has high wear resistance, but the samples made of 16 and $20 \%$ with snail shell powder have less frictional force compared to $12 \%$ [6]. Composites reinforced with a snail shell powder fabricated with $15-20 \%$ wt have good flexural strength whereas $20 \%$ wt sample shows high tensile strength compared to other samples. The optimum $\%$ of wt is within $5-20$ as $25-30$ wt $\%$ gives abnormal results and can be a replacement of pure polyester based applications [7]. The thermal, mechanical and electrical properties of grapheme filled goat hair fiber reinforced epoxy composites are good with $37.5 \%$ fiber content by weight. The compared results of non-grapheme based composites have inferior properties than the grapheme filled composites [8]. The hybrid composite made of sea shell and snail shell powder of $30 \mathrm{wt} \%$ has enhanced in hardness compared to sample made of 15 wt $\%$ [9].

\section{PREPARATION AND TESTING OF COMPOSITES}

\subsection{Preparation}

The most abandoned waste which is biodegradable is goat hair, horns and snail shells. In this work, the composite specimens are fabricated using commercially available EPOXY Resin LY 556 along with hardener HY 951 and goat hair, goat horn and snail shell powders. The different proportions of these materials are mixed to fill in the G. I sheet molds of dimensions 200mmX200mmX15mm using the hand lay-up technique as shown in Fig. 2. In total 7 samples are prepared and the methodology followed is shown in Fig.1.

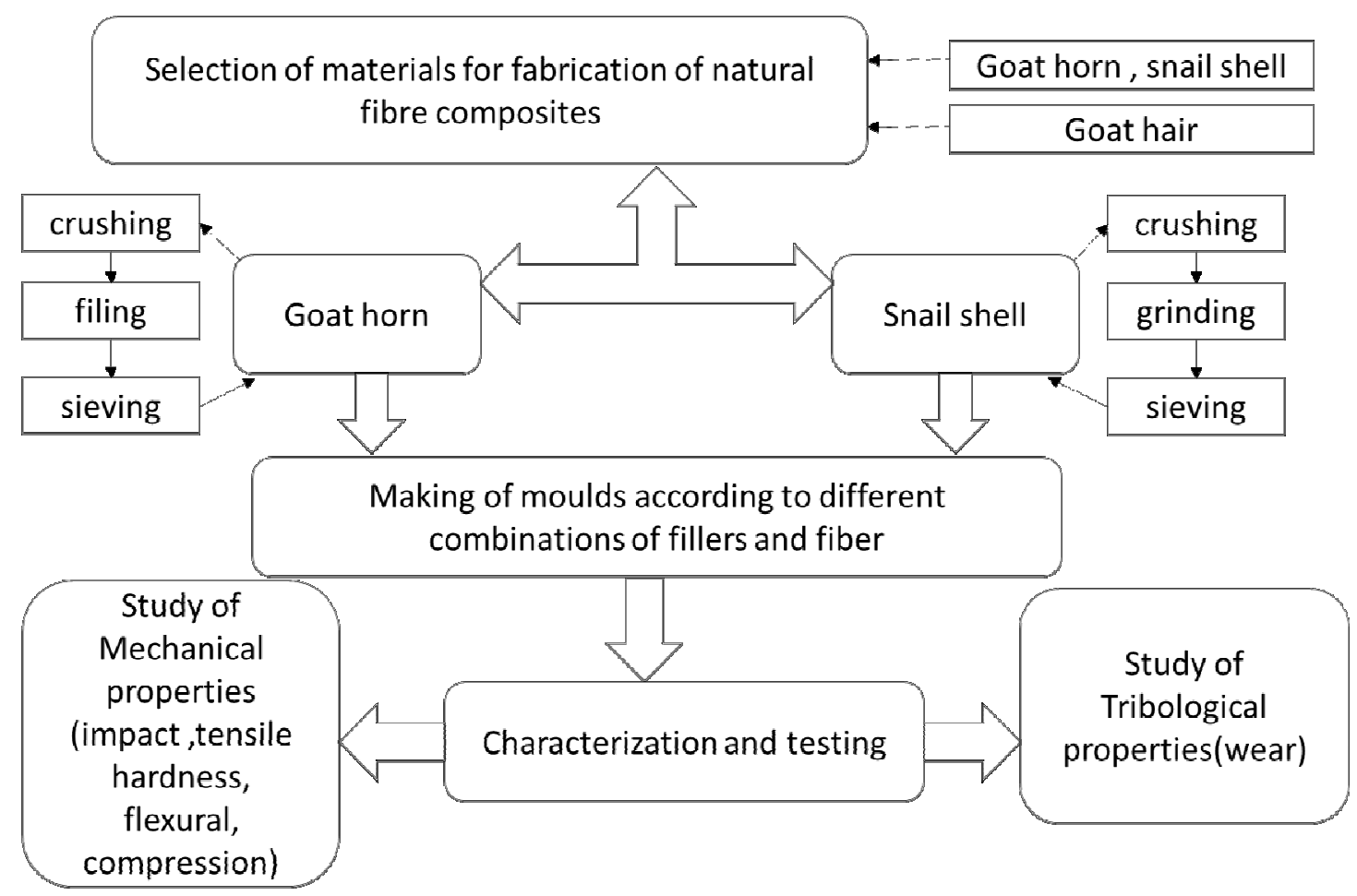

Figure 1: The Methodology Followed for Composite Sample Preparation 

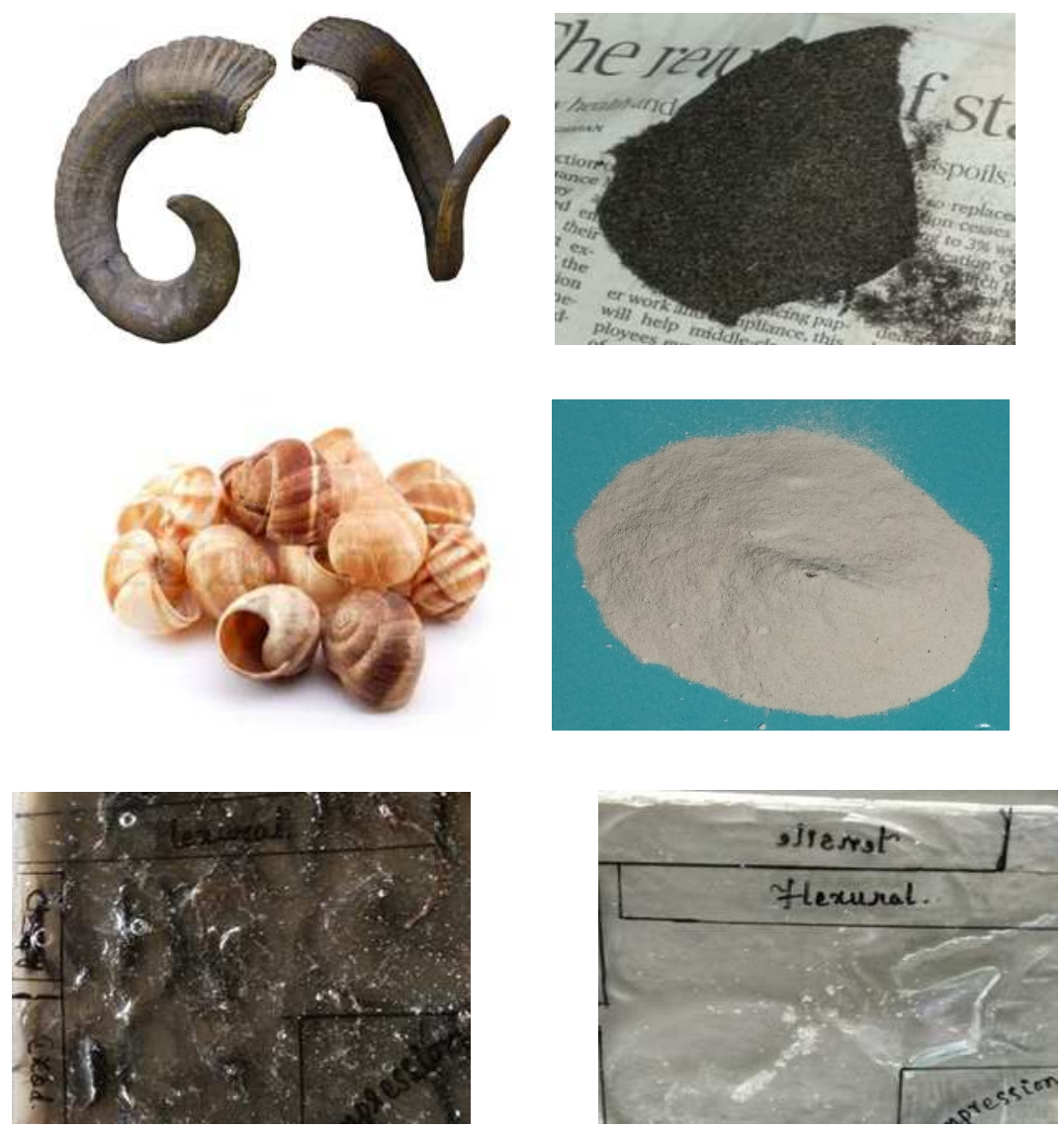

Figure 2: Filler Materials used and Composites prepared using Hand lay-up Technique a)Goat Horns, b) Horn powder, c) Snail shells d) Shell powder, e) Goat hair +Goat horn composite and f) snail shell powder reinforced composite

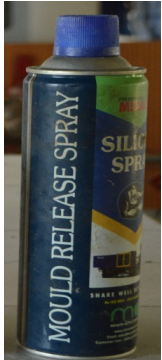

Silicone spray

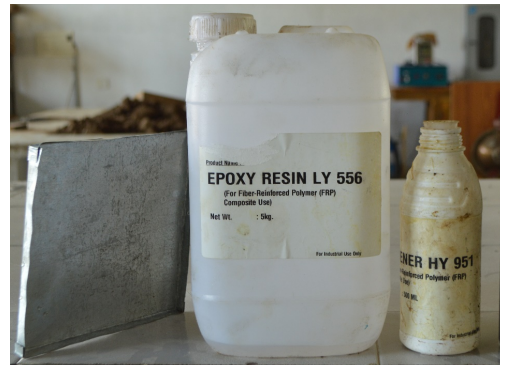

Resin LY556 Hardener HY951

Figure 3: Resin, Hardener and Silicone Spray used for the Preparation Of Natural Composites

Silicone spray is used to because it has excellent anti stick \release property, anti -friction property resistance to moisture, humidity and corrosion. It also provides shine on plastic, metal, glass and painted wooden surfaces. It also have compatibility with most plastics and rubber, Non-staining, non-carbonizing and nontoxic in nature. 


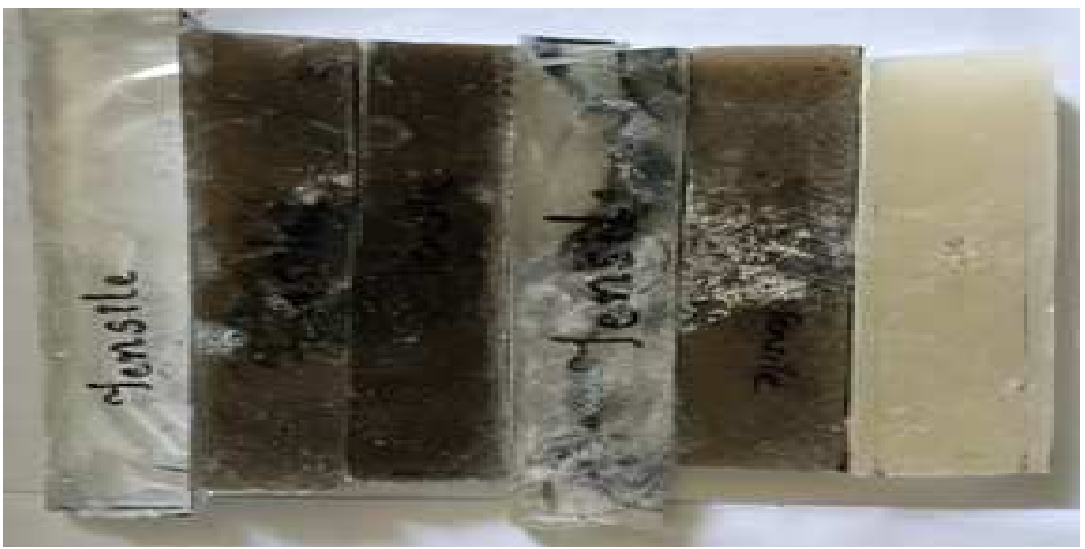

Figure 4: Specimens cut to test the Various Mechanical Properties The properties of seven specimens prepared and tested are shown in Table.1.

\subsection{Mechanical Properties Testing of Composites}

The various tests (Tensile, flexural, compression, hardness, impact) were conducted on the composite specimens shown in Fig. 4 to understand the behavior under various conditions.

Table 1. Mechanical properties of Composite specimens

\begin{tabular}{|c|c|c|c|c|c|}
\hline SI. No. & $\begin{array}{c}\text { Tensile Strength } \\
(\mathbf{M P a})\end{array}$ & $\begin{array}{c}\text { Flexural Strength } \\
(\mathbf{M P a})\end{array}$ & $\begin{array}{c}\text { Impact Strength } \\
\left(\mathbf{J} / \mathbf{m m}^{\mathbf{2}}\right)\end{array}$ & $\begin{array}{c}\text { Compression Strength-Peak load } \\
(\mathbf{K N})\end{array}$ & $\begin{array}{c}\text { Hardness } \\
(\mathbf{R H N})\end{array}$ \\
\hline 1 & 11.47 & 270 & 0.2 & 19.8 & 6 \\
\hline 2 & 4.47 & 67.5 & 0.4 & 24.3 & 30 \\
\hline 3 & 12.67 & 225 & 0.08 & 26.1 & 25 \\
\hline 4 & 4.47 & 67.5 & 0.12 & 31.3 & 50 \\
\hline 5 & 15.30 & 90 & 0.04 & 52.9 & 20 \\
\hline 6 & 16.78 & 67.5 & 0.44 & 37.5 & 20 \\
\hline 7 & 12.67 & 75 & 0.16 & & 34 \\
\hline
\end{tabular}



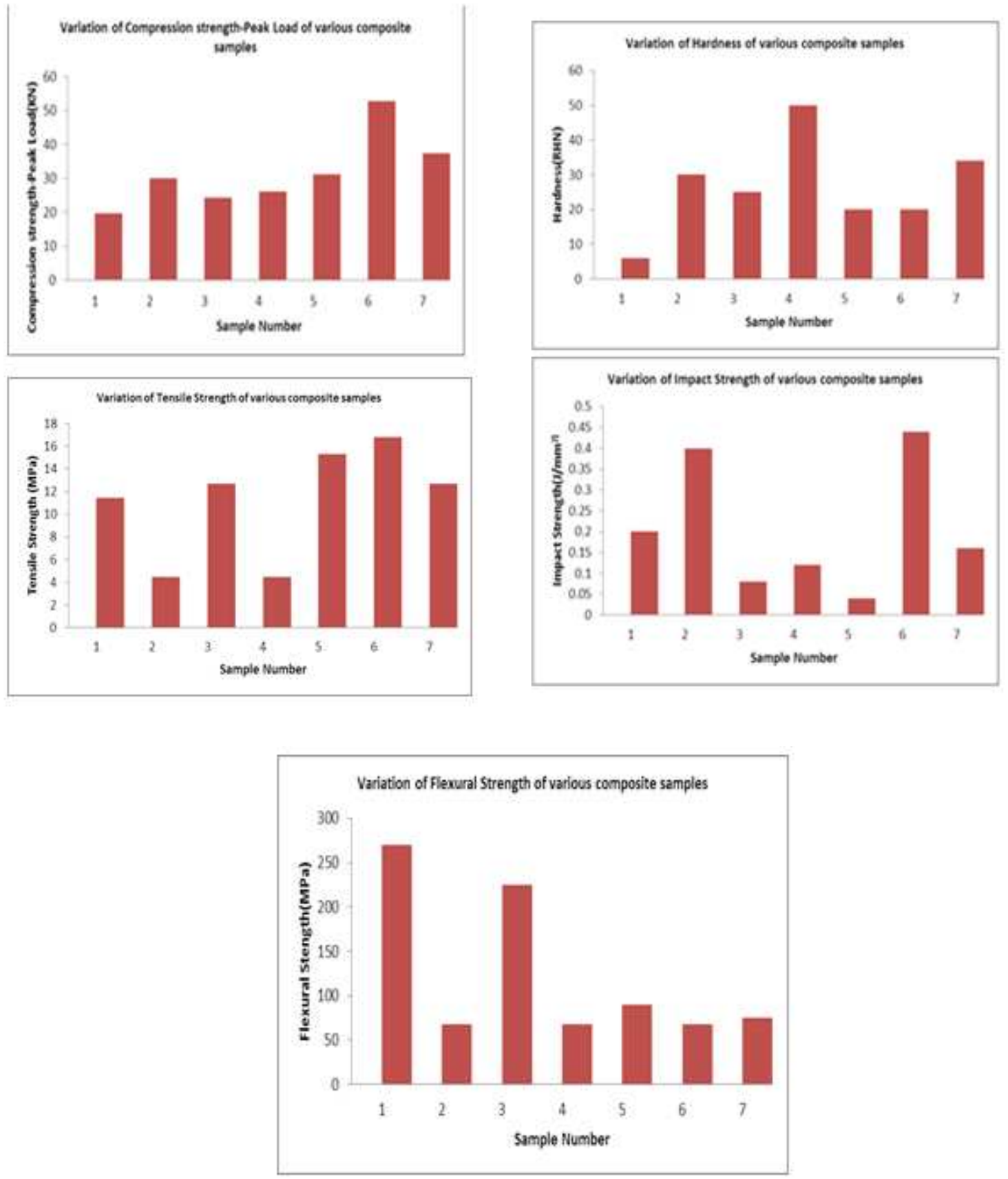

Figure 4: Test results of composite specimens(Tensile, Flexural, compression, hardness and impact strength)

From the results shown in Table.1, it is identified that for some of the composite samples the mechanical properties like tensile strength, compressive strength, flexural strength and impact strength are enhanced with the addition of fillers in the fabrication, whereas hardness value is decreased for some samples. The Tensile strength is increased in all the specimens. Tensile strength $(15.3 \mathrm{MPa})$ is highest in the specimen which is made with only horn powder as filler and impact strength $(0.44$ joule $/ \mathrm{mm}^{2}$ ) is maximum for the composite made of horn powder, shell powder and goat hair fiber. The compressive strength is high for the composite made of snail shells, horn powder and goat hair fiber, which withstands a peak load of $52.9 \mathrm{kN}$.

\subsection{Testing of Tribological Properties of Composites}

The experimental setup used to study the Tribological properties is shown in Fig. 5(a). The experimentation is done with three 
materials used for making of pins namely shell, horn and composite with both shell and horn powders. The disc and pin detailed drawings used fot the preparation of pure epoxy with dimensions is shown in Fig 5(a,b). Disc and Pins before and after testing are shown in Fig 5(c) and (d) respectively. The testing conditions are given in Table 2. The length of the pins used for the experimentation are of $40 \mathrm{~mm}$ length and $4 \mathrm{~mm}$ diameter. The POD setup used for this study can be able to accommodate pins of diameters of 4,6 and $8 \mathrm{~mm}$ resepectively. The pins are usually in hemi spherical shape and after each experiment some amount of material will be lost and that can be used to estimate the volume loss. Here in this study the LVDT sensor which is supporting the load and pin is continuously in contact with the disc. Whatever the load applied on the one end of the lever will be applied on the disc by the pin. It also consists of a linear variable differential transducer (LVDT) which will give the amount of wear on the pin and disc during the test.

The normal load, rotational speed and wear track diameter can be varied to suit test conditions. Tangential frictional force and wear are monitored with electronic sensors and recorded on PC. These parameters are available as functions of load and speed.

This setup is connected to the PC which supports the winducom software. The software provides the graphs that are plotted during each experimentation (Fig. 5(e)). Later the average values of wear, coefficient of friction and frictional force can be used for understanding the tribological behaviour of the natural composites.

The Sliding distance is calculated as follows:

$$
\text { Sliting distanco }(m)=\frac{\pi \times D \times N \times T}{60000}
$$
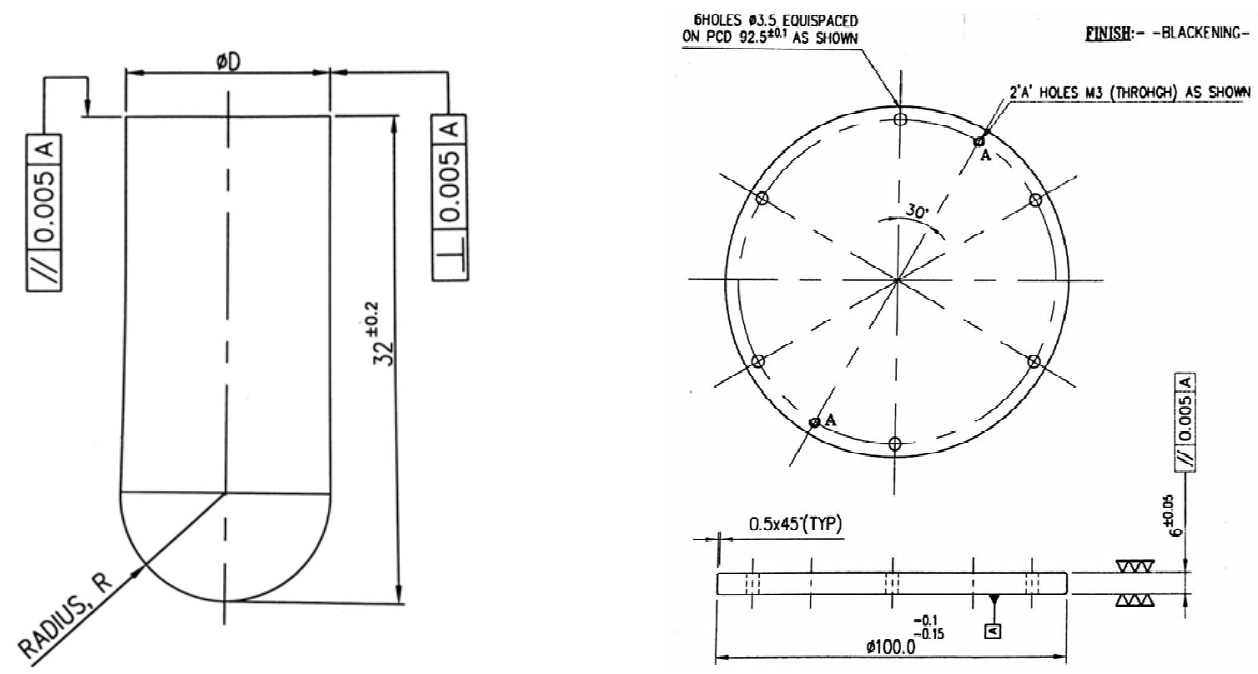

Where $\mathrm{D}$ is considered in between 40-60mm,

$\mathrm{N}$ is the rotational speed of the disc and $\mathrm{T}$ is the time considered for the experiment.

\section{(a) Detailed Drawing of the Disc used for the Experimentation (b) Detailed drawing of the pin used for the Experimentation}




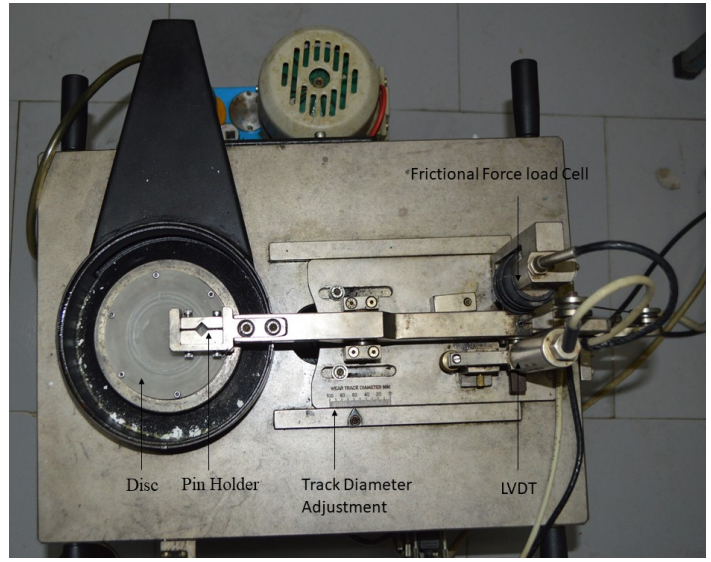

(c) Experimental setup

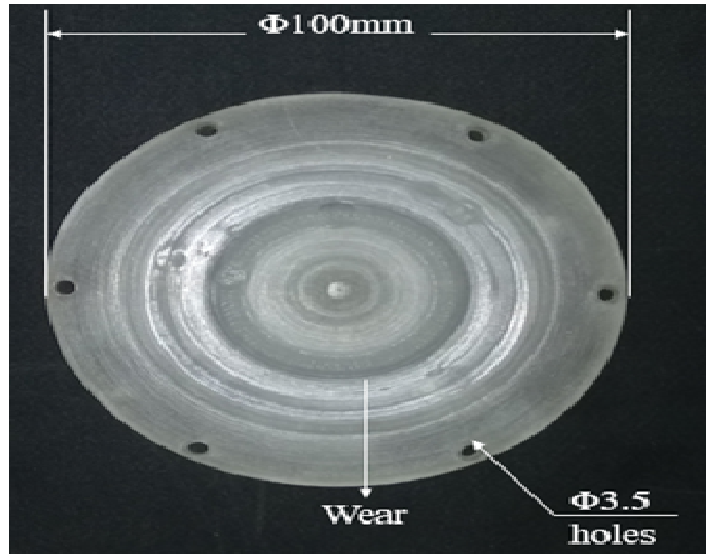

Before the test
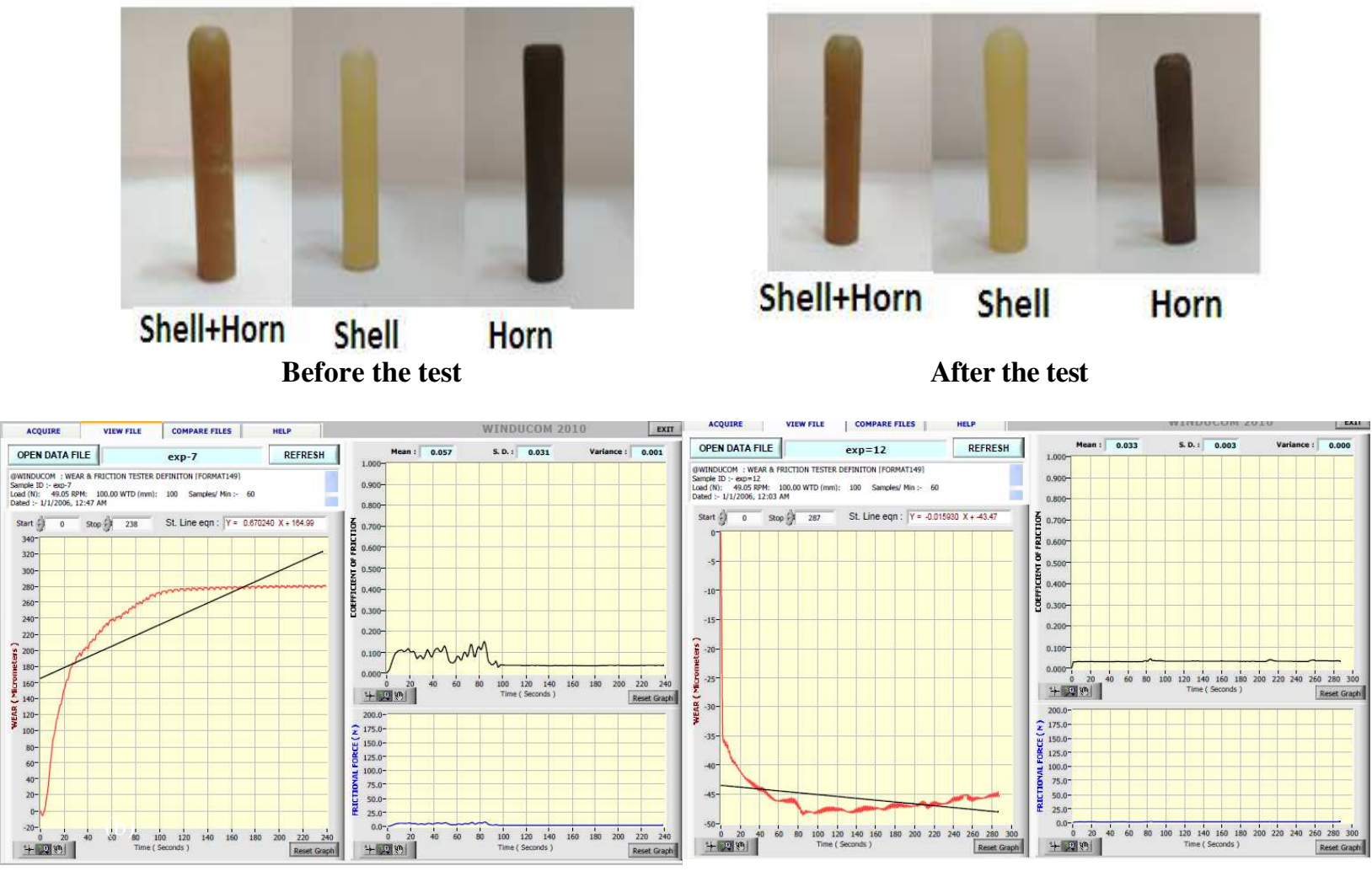

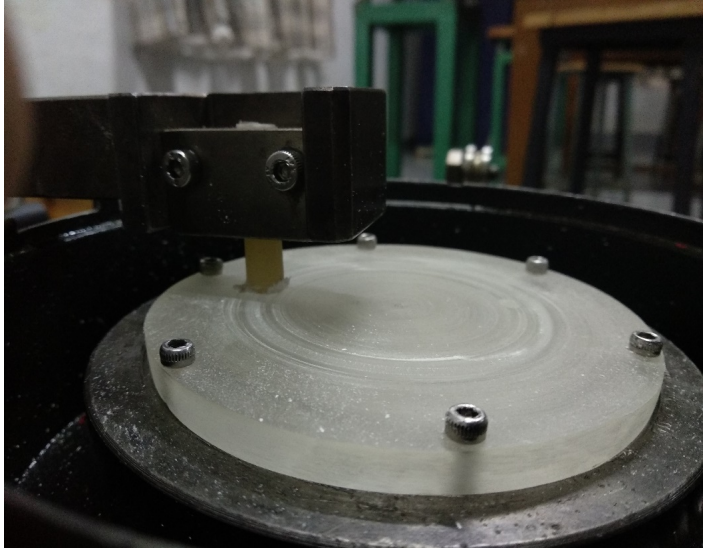

After the test
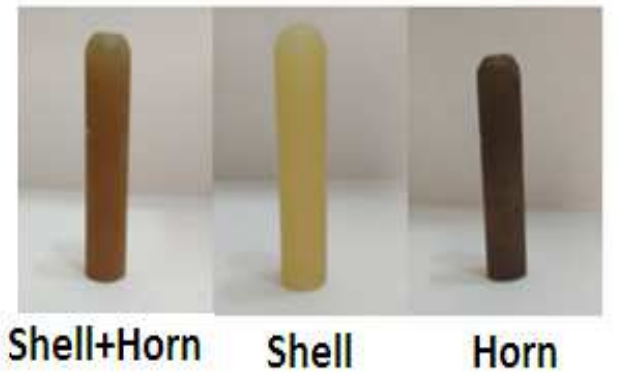

After the test 
(d) Discs and Pins used for experimentation

\section{$7^{\text {th }}$ Experimental condition}

$12^{\text {th }}$ Experimental condition

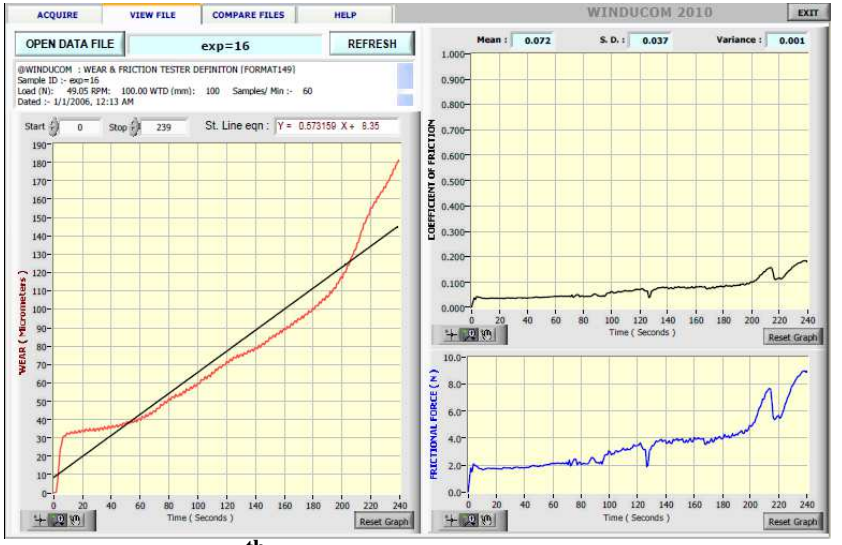

$1^{\text {th }}$ Experimental condition

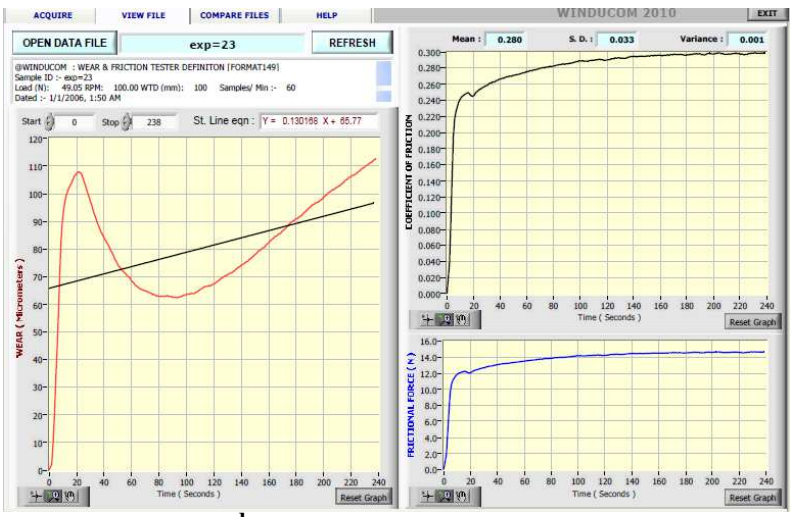

${23^{\text {rd }}}^{\text {Experimental condition }}$

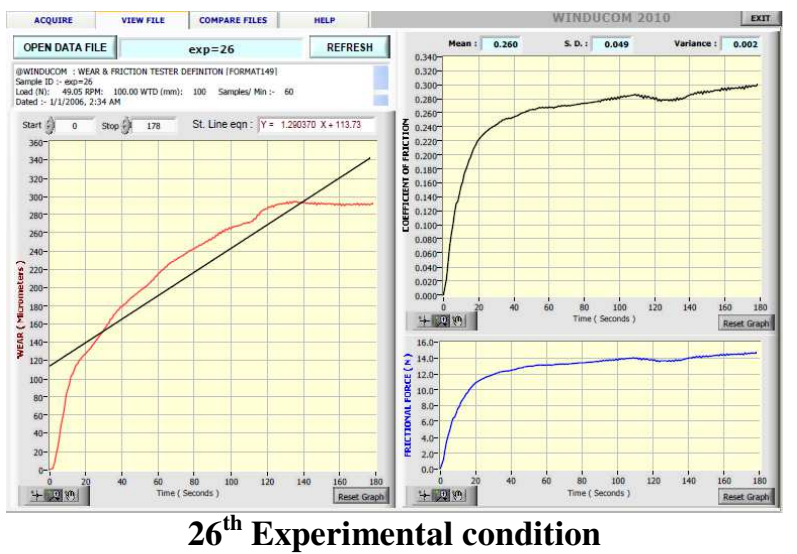

(e) Graphs captured using winducom software

Figure 5: Experimental Details

The experimental conditions are developed by taking a taguchi L24 orthogonal array using Minitab 16.0 software. The variables considered for the present study are rotational speed, time, load and sliding distance.

Taguchi design of experiments methodology is applied so that the experimental conditions can be selected based on judgmental sampling not like the random selection. Its also helps in reducing the number of repetitions which are generally being identified in traditional methods. 
Further it can be used to identify the most influencing factor and level by perfoming the signal to noise ratio analysis and analysis of variance.

\section{RESULTS \& DISCUSIONS}

Affter each test as per Table 2 the results are noted and the Tribological results obtained are shown in graphical representation and comparison is done as shown in Figs 6 and 7, which shows the variation of wear and frictional force with respect to the sliding distance. The graphs consists of wear and frictional force of three types of pins like pure shell pure horn and a composite of horn and shell powders.

Table 2: Experimental Conditions

\begin{tabular}{|c|l|c|c|c|c|}
\hline Sl. No. & Specimen type & $\begin{array}{c}\text { Rotational Speed } \\
(\mathbf{r p m})\end{array}$ & $\begin{array}{c}\text { Time } \\
(\mathbf{S e c})\end{array}$ & Sliding Distance (m) & $\begin{array}{c}\text { Load } \\
(\mathbf{k g})\end{array}$ \\
\hline 1. & Horn & 150 & 180 & 84.82 & 2 \\
\hline 2. & Shell & 150 & 180 & 84.82 & 2 \\
\hline 3. & Horn+Shell & 150 & 180 & 84.82 & 2 \\
\hline 4. & Shell & 200 & 240 & 125.66 & 2 \\
\hline 5. & Horn & 200 & 240 & 125.66 & 2 \\
\hline 6. & Horn+Shell & 200 & 240 & 125.66 & 2 \\
\hline 7. & Horn & 200 & 120 & 62.83 & 2 \\
\hline 8. & Shell & 200 & 120 & 62.83 & 2 \\
\hline 9. & Horn+Shell & 200 & 120 & 62.83 & 2 \\
\hline 10. & Horn+Shell & 150 & 120 & 47.12 & 2 \\
\hline 11 & Shell & 150 & 120 & 47.12 & 2 \\
\hline 12. & Horn & 150 & 120 & 47.12 & 2 \\
\hline 13. & Horn & 150 & 240 & 94.24 & 1.5 \\
\hline 14. & Shell & 150 & 240 & 94.24 & 1.5 \\
\hline 15. & Horn+Shell & 150 & 240 & 94.24 & 1.5 \\
\hline 16. & Horn+Shell & 200 & 300 & 188.49 & 1.5 \\
\hline 17. & Horn & 200 & 300 & 188.49 & 1.5 \\
\hline 18 & Shell & 200 & 300 & 188.49 & 1.5 \\
\hline 19 & Horn+Shell & 200 & 120 & 75.39 & 1.5 \\
\hline 20. & Horn & 200 & 120 & 75.39 & 1.5 \\
\hline 21. & Shell & 200 & 120 & 75.39 & 1.5 \\
\hline 22. & Horn+shell & 150 & 240 & 113.097 & 1.5 \\
\hline 23. & Horn & 150 & 240 & 113.097 & 1.5 \\
\hline 24. & Shell & 240 & 113.097 & \\
\hline & & & & 2 \\
\hline
\end{tabular}




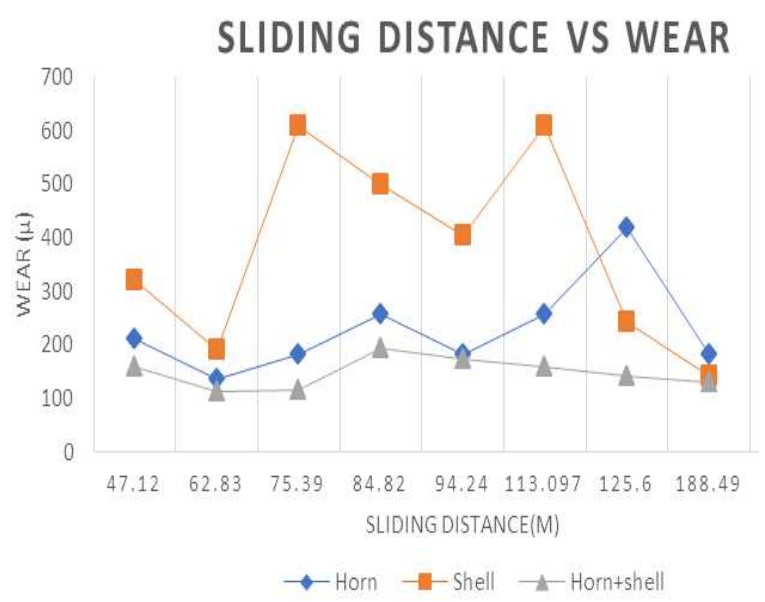

Fig.6. Variation of Wear with respect to Sliding distance for different samples

SLIDING DISTANCE VS FRICTIONAL

FORCE

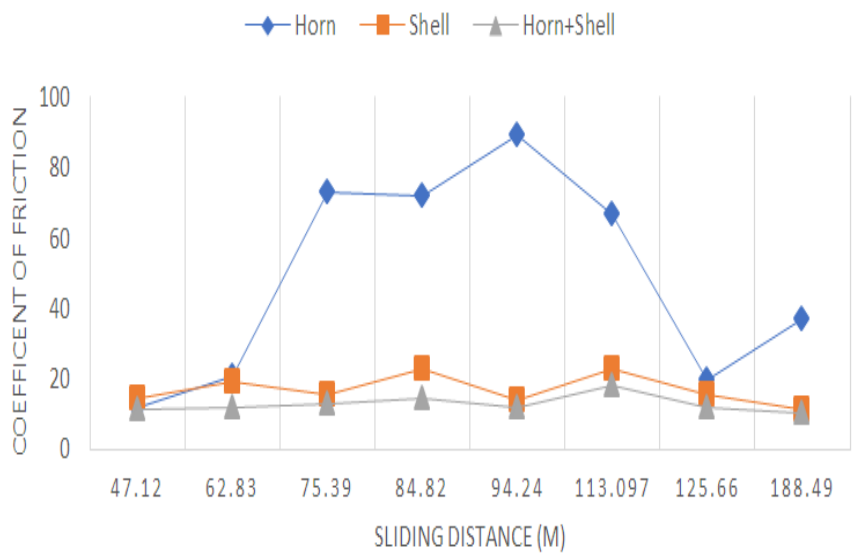

Figure 7: Variation of frictional force with respect to Sliding distance for Different Samples

In Fig.6. The variation of wear with respect to the sliding distance for three composites made of pure horn, pure shell and combination of horn and shell materials is shown. The graph shows that the wear is minimum for the hybrid composite made of horn and shell powders compared to composites made of either pure shell or pure horn powders.

Similarly, the frictional force is minimum for the hybrid composite(Horn+shell) compared to the composite made of either horn or shell powders as depicted in Fig. 7.

\section{CONCLUSIONS}

The natural composites (seal shell powder, horn powder and horn+shell powder) made from the unwanted, abandoned bio waste. These composites are cost effective, biodegradable, Eco friendly and can be a better replacement for polymer composites. These green composites can be used to increase the mechanical and Tribological properties of components. The experimental results revealed that the tensile strength is increased in all the specimens. The tensile strength(15.3 MPa) is highest in specimen made with only horn powder as filler and the highest impact strength $\left(0.44\right.$ joule $\left./ \mathrm{mm}^{2}\right)$ is observed for the hybrid composite made of horn, shell powders with goat hair as fiber. It is also observed that the compressive strength is high for the composite made of snail shell, horn powder and goat hair, which was able to withstand a peak load 
of about 52.9kN. The Tribological performance of hybrid composite is better than the composites made of either pure horn or pure shell powders. As a result, the bio waste can be utilized in composites manufacturing which exhibits better results.

\section{REFERENCES}

1.Kumar, D,(2016). Investigation on Tribological Properties of Horn Fiber Reinforced Epoxy Composites, Int.J.of Mechanical \& Mechatronics Engineering, 16(3), 79-87.

2.Ahmad, S, (2014). Preparation of eco-friendly natural hair fiber reinforced polymeric composite (FRPC) material by using of polypropylene and fly ash: a review, Int.J.of Scientific \& Engineering Research,5(11), 2229-5518.

3.Baptista, Ricardo, Ana Mendão, Mafalda Guedes, and Rosa Marat-Mendes,(2016), An experimental study on mechanical properties of epoxy-matrix composites containing graphite filler, Proceedings of XV Portuguese Conference on Fracture, 7481, Procedia Structural Integrity, Portugal.

4.Oladele, I. O., Olajide, J. L., \& Amujede, M., (2016). Wear Resistance and Mechanical Behaviour of Epoxy/Mollusk Shell Biocomposites developed for Structural Applications, Tribology in Industry, 38(3), 347-360.

5.Ramnath, B. Vijaya, J. Jeykrishnan, G. Ramakrishnan, B. Barath, and E. Ejoelavendhan,.(2018). Sea Shells And Natural Fibres Composites: A Review, Materials Today: Proceedings 5(1), 1846-1851.

6.Karthick, R., P. Sirisha, and M. Ravi Sankar..(2014). Mechanical and tribological properties of PMMA-sea shell based biocomposite for dental application, 3rd International Conference on Materials Processing and Characterization, Procedia materials science,6, 1989-2000.

7.Isiaka, Oladele, Adeyanju Bayode, and Olarotimi Abosede., Characterization of snail shell reinforced polyester composites, Int.J.of Research and Engineering, 4(9), 236-240.

8.Jayaseelan, J., P. Palanisamy, K. R. Vijayakumar, and A. Dhanam Maria Vinita,.(2015), Effect of Graphene Filler Content on Mechanical Strength and Hardness for Goat Hair Fibre Reinforced Epoxy Composites, Int.J.of Vehicle Structures \& Systems, 7(4), 165-168.

9.Odusanya, Abiodun Ademola, Babatunde Bolasodun, and Chioma Ifeyinwa Madueke..(2014) Property evaluation of hybrid seashell/snail shell filler reinforced unsaturated polyester composite in comparison with seashell and snail shell filler reinforced unsaturated polyester composite, The Int. J.of Engineering and Science, 3, 80-90.

10.Venkategowda, T., \& Lh, M. Free Vibration Characteristics Of Alkali Treated Unidirectional Long Kenaf Fiber Reinforced Epoxy Composites At Various End Conditions.

11.Sudindra, S., Prasad, G., \& Nagaral, M. Design And Analysis Of Connecting Rod Material Made By B4c Reinforced Al7075 Alloy Heat Treated Composites.

12.Seldon, P. A., \& Abilash, N. Assessment On Divergent Reinforced Polymeric Composites Of Natural Fiber. 

